\title{
Analisis Preventive Maintenance Pada Mesin Produksi dengan Metode Fuzzy FMEA
}

\author{
Sri Susilawati Islam ${ }^{1 *}$, Tika Lestari ${ }^{2}$, Anisa Fitriani $^{3}$, Dilla A Wardani ${ }^{4}$ \\ ${ }^{1 *, 2,3,4)}$ Universitas Sampoerna \\ *sri.islam@sampoernauniversity.ac.id
}

\begin{abstract}
Machine maintenance activities are activities that have a very important role to support the smooth production process. Irregular maintenance can cause the machine to experience disruption or damage (downtime), this can hamper the smooth production process. So that the production process can run according to plan, it must be supported by a reliable machine state so that a good engine maintenance plan is needed. Preventive maintenance is one of the most widely used maintenance plans to ensure that the machine can run according to its function. In this research, a case study was conducted at PT PLN Tello Makassar Sector because the company has an important role in supplying electric current in the city of Makassar, amounting to $197.61 \mathrm{MW}$. If there is an engine failure it will have an impact on the economic activities of the community which can cause losses, currently the maintenance planning undertaken by PT PLN in the Tello Makassar Sector has not been running optimally because there is still a generator engine failure during the production process. So that engine failure can be reduced, this study will use the Fuzzy FMEA (Failure Mode and Effect Analysis) method to identify machine damage and determine engine priority in the maintenance process and type of treatment based on the RPN (Risk Priority Number) value. According to the data processing, the highest value of Fuzzy RPN are Cylinder, CVS Lubricant Fast Lanes, CVS Lubricant Pipe, and Rocker Arms which is 155.333 .
\end{abstract}

Keywords: Fuzzy FMEA, severity, occurance, detection, risk priority number

\begin{abstract}
Abstrak
Kegiatan perawatan mesin (maintenance) merupakan kegiatan yang memiliki peran yang sangat penting untuk menunjang kelancaran proses produksi. Maintenance yang tidak teratur dapat mengakibatkan mesin mengalami gangguan atau kerusakan (downtime), hal ini dapat menghambat kelancaran proses produksi. Agar proses produksi dapat berjalan sesuai dengan perencanaan, maka harus ditunjang dengan keadaan mesin yang handal sehingga diperlukan perencanaan perawatan mesin yang baik. Pereventive maintenance merupakan salah satu perencanaan perawatan yang banyak digunakan untuk memastikan bahwa mesin dapat berjalan sesuai dengan fungsinya. Pada penelitian ini, studi kasus dilakukan di PT PLN Sektor Tello Makassar sebab perusahaan tersebut mempunyai peranan penting dalam menyuplai arus listrik di kota Makassar yaitu sebesar 197,61 MW. Jika terjadi kerusakan mesin maka akan berdampak pada aktivitas ekonomi masyarakat yang dapat menyebabkan kerugian, saat ini perencanaan maintenance yang dilakukan oleh PT PLN Sektor Tello Makassar belum berjalan optimal karena masih terjadinya kerusakan mesin generator saat proses produksi berlangsung. Agar kegagalan mesin dapat dikurangi, maka penelitian ini akan menggunakan metode Fuzzy FMEA (Failure Mode and Effect Analysis) untuk mengidentifikasi kerusakan mesin dan menentukan prioritas mesin dalam proses perawatan serta jenis perawatannya berdasarkan nilai RPN (Risk Priority Number). Berdasarkan perhitungan dengan menggunakan excel, maka nilai RPN terbesar adalah Cylinder, Pipa pelumas CVS, Jalur cepat pelumasan CVS, dan rocker arm yang mempunyai nilai Fuzzy RPN sebesar 155,33.
\end{abstract}

Kata kunci: Fuzzy FMEA, severity, occurance, detection, risk priority number 


\section{Pendahuluan}

Kegiatan maintenance merupakan kegiatan yang dilakukan untuk memperbaiki kerusakan dan meningkatkan performansi mesin (1). Kegiatan maintenance sangat penting dalam sebuah industri karena kebutuhan akan jaminan performansi yang berkualitas tinggi baik dalam era automatisasi dan juga pada proses produksi yang terus meningkat. Jika mesin tidak dapat beroperasi secara optimal, maka proses produksi akan terhenti. Oleh karena itu, melakukan kegiatan perawatan pada pada sebuah mesin sebelum terjadi kerusakan menjadi sangan penting pada sebuah industrikarena dapat mengurangi biaya perbaikan mesin dan daat menjaga kualitas produk (2).

\subsection{Jenis-Jenis Perawatan}

Penelitian terdahulu[3] telah membagi perawatan menjadi empat kategori yaitu reactive maintenance, preventive maintenance, predictive maintenance, dan proactive maintenan seperti yang diperlihatkan pada Gambar 1.

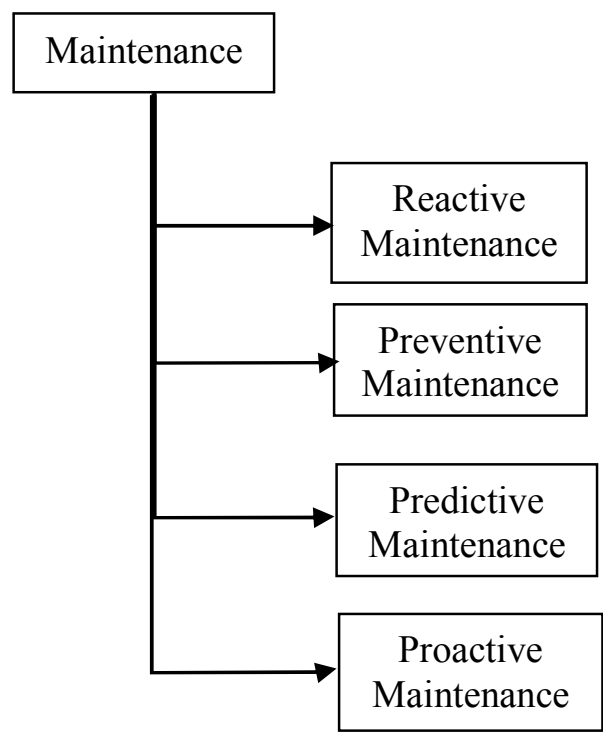

Gambar 1. Kategori Perawatan

\section{a. Reactive Maintenance}

Reactive Maintenance merupakan tindakan perawatan yang dilakukan pada saat mesin mengalami kerusakan mesin. Kegiatan perawatan yang dilakukan dengan reactive maintenance akan menyebabkan biaya yang besar karena akan menyebabkan downtime secara tiba-tiba. Hal ini disebabkan karena tidak adanya perencanaan perawatan.

\section{b. Preventive Maintenance}

Preventive maintenance merupakan tindakan perawatan secara berkala berdasarkan perencanaan perawatan. Kegiatan perawatan ini merupakan tinadakan perawatan yang dilakukan berdasarkan waktu perawatan yang telah direncanakan tanpa menunggu terjadinya kerusakan mesin.

\section{c. Predictive Maintenance}

Predictive maintenance yaitu analisis kondisi peralatan berdasarkan perilaku peralatan saat beroperasi, sehingga dari analisis tersebut dapat diprediksi kapan peralatan dapat beroperasi secara normal

\section{d. Proactive Maintenance}

Proactive maintenance merupakan proses perawatan yang dilakukan oleh seseorang yang sangat paham dengan keadaan mesinnya (operator produksi, sehingga sebelum memulai proses produksi maka akan dilakukan tindakan perbaikan sebelum terjadi kerusakan pada mesin.

\subsection{Metode Analisis Kegagalan}

Sebelum melakukan tindakan perawatan, maka terlebih dahulu dilakukan analisis kerusakan kerusakan mesin agar tindakan perbaikan sesuai dengan jenis kerusakan. Ada berbagai macam alat yang digunakan untuk menganalisis dan mengetahui sumber-sumber serta akar penyebab kerusakan yang terjadi. (1) menggunakan analisis fishbone diagram untuk mencari akar permasalahan penyebab tidak efisiensinya proses bisnis yang ada di sebuah rumah sakit. Root Causes Analysis (RCA) digunakan oleh (2) untuk menganalisis aktivitas yang sifatnya non value added pada perusahaan jasa yang bergerak dibidang warehousing, forwarding, dan ekspedisi. (3) menggunakan 
analisis Failure Mode and Effect Analysis (FMEA) untuk mengidentifikasi penyebab kerusakan dan membuat mitigasi resiko berdasarkan peringkat kerusakan.

Pada penelitian ini, metode yang akan digunakan adalah metode Fuzzy FMEA. Sudah ada beberapa penelitian sebelumnya yang menggunakan metode Fuzzy FMEA, metode ini digunakan untuk menganalisis terjadinya sebuah resiko dan tingkat prioritas dari resiko tersebut (3).

\subsection{Failure Mode and Effect Analysis (FMEA)}

FMEA merupakan metode sistematik yang digunakan untuk mengidentifikasi dan mencegah terjadinya masalah pada suatu produk dan proses manufaktur. Analisis FMEA pada produk digunakan untuk analisis pada mode Pada Gambar 1 memperlihatkan tahap awal adalah melakukan tinjauan proses, hal ini sangat penting untuk mendapatkan gambaran proses secara keseluruhan dari sistem yang menjadi objek analisis. Setelah itu pada tahap 2 dan 3, dilakukan pembentukan tim analisis dimana tim tersebut akan menentukan langkah-langkah /proses analisis yang akan dilakukan. Setelah penentuan langkah analisis maka dilanjutkan pada tahap 4 dengan melakukan proses identifikasi kegagalan/kerusakan, mode kegagalan, dan penyebab kegagalan.

Pada analisis kegagalan, ada tiga kriteria yang akan dinilai yaitu: severity $(\mathrm{S})$ merupakan tingkat kegagalan/kerusakan yang terjadi, occurance (O) merupakan indeks terjadinya kegagalan, dan detection (D) merupakan kemampuan untuk mendeteksi terjadinya kegagalan. Setelah ketiga kriteria kegagalan tersebut diperoleh, maka tahap 5 adalah menghitung Risk Priority Number (RPN) yang dipeoleh dari hasil perkalian ketiga kriteria pada tahap 4 . Hasil dari nilai RPN kemudian dievaluasi dan dianalisis sebagai acuan dalam membuat langkah perbaikan pada tahap 6 .

kegagalan yang disebabkan karena ketidakefisiensian dari suatu produk yang dihasilkan oleh manufaktur maupun jasa (4).
FMEA pada proses manufaktur digunakan untuk menganalisis resiko pada setiap tahapan proses produksi (4). Tujuan utama dari FMEA adalah mencegah terjadinya cacat, meningkatkan keselamatan kerja, dan kepuasan pelanggan (4). Sementara[4] menjelaskan ada enam tahap dalam melakukan analisis FMEA. Tahapan tersebut dapat dilihat pada Gambar 2.

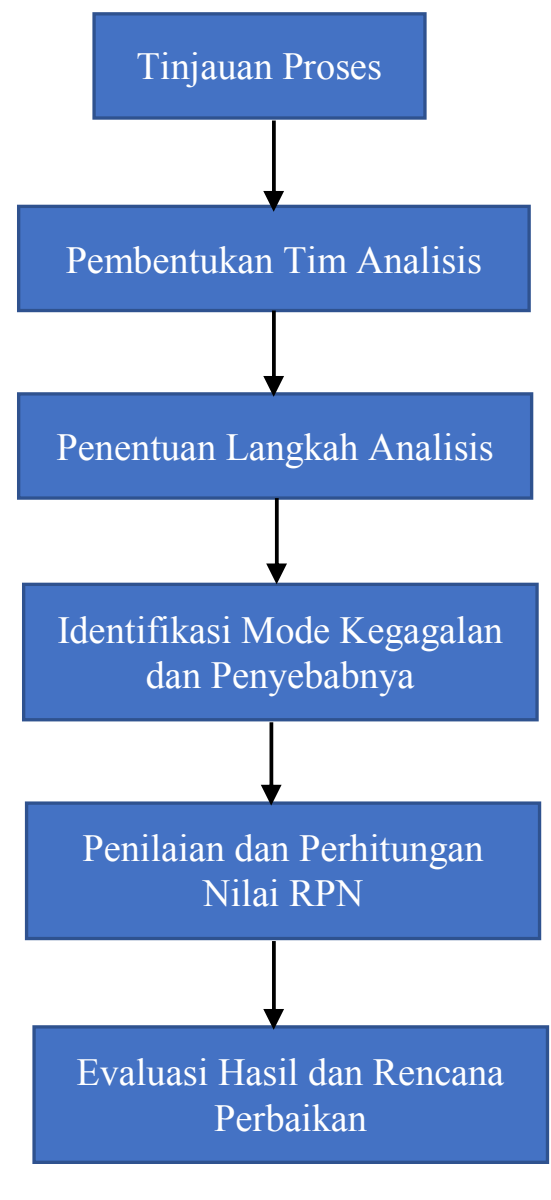

Gambar 2. Tahapan Analisis FMEA

\subsection{Fuzzy Logic}

Widianti menjelaskan bahwa Logika Fuzzy memberikan dasar berpikir dengan metode pendekatan, yaitu cara berpikir yang menyatakan bahwa suatu unsur dapat tidak sepenuhnya menjadi anggota suatu himpunan tertentu. Hal ini berbeda dengan teori logika klasik yang menyatakan bahwa segala sesuatu bersifat biner, yang artinya hanya mempunyai dua kemungkinan, "Ya atau Tidak" dengan nilai keanggotaan 1 atau 0. Himpunan fuzzy menjelaskan suatu konsep berdasarkan premis bahwa unsur- 
unsur yang digunakan adalah bukan dalam bentuk angka-angka melainkan terkait dengan istilah linguistik[5].

Sedangkan Royani[6] menjelaskan keunggulan dari logika fuzzy:

a. Konsep yang mendasari penalaran fuzzy adalah konsep matematis yaitu teori himpunan sehingga mudah dimengerti.

b. Logika fuzzy yang sangat fleksibel.

c. Logika fuzzy memiliki toleransi terhadap data-data yang tidak tepat.

d. Logika fuzzy mampu memodelkan fungsi-fungsi non linier yang sangat kompleks.

e. Logika fuzzy dapat membangun dan mengaplikasikan pengalamanpengalaman para pakar secara langsung tanpa harus melalui proses pelatihan.

f. Logika fuzzy dapat bekerjasama dengan teknik-teknik kendali secara konvensional.

g. Logika fuzzy didasarkan pada bahasa alami.

Metode Mamdani adalah salah satu metode yang sering digunakan dalam logika fuzzy. (7) melakukan penelitian dengan menggunakan metode Mamdani dengan menggunakan operasi $M I N-M A X$ atau $M A X$ $P R O D U C T$. Berikut adalah langkah-langkah dari metode Mamdani:

a. Fuzzyfikasi atau pembentukan himpunan fuzzy.

b. Pembentukan basis pengetahuan fuzzy (rule dalam bentuk IF.....THEN).

c. Aplikasi fungsi implikasi menggunakan fungsi MIN dan Komposisi antar-rule menggunakan fungsi MAX (menghasilkan himpunan fuzzy baru).

d. Defuzzyfikasi (penegasan)

(8) menjelaskan Ada beberapa metode defuzzyfikasi pada komposisi aturan, salah satunya adalah Metode Centroid (Composite Moment), dimana solusi crisp diperoleh dengan cara mengambil titik pusat daerah fuzzy.

\section{Metode Penelitian}

Penelitian ini berfokus pada preventive maintenance untuk mencegah terjadinya kerusakan pada mesin dengan menggunakan metode Fuzzy FMEA. Tujuan dari penggunaan metode Fuzzy FMEA adalah untuk mengevaluasi tindakan perawatan dan periode perawatan yang sesuai kebutuhan PT PLN Sektor Tello yang ditinjau berdasarkan hasil analisis yang telah dilakukan. PT PLN Sektor Tello merupakan perusahaan milik pemerintah yang mempunyai peranan penting dalam menyalurkan listrik di kawasan Makassar sebesar 197,61 MW.

Dalam menghasilkan listrik sebesar 197,61, PT PLN Sektor Tello menggunakan mesin generator sebagai mesin pembangkit tenaga listrik. Sehingga mesin generator mempunyai peranan yang sangat krusial dan sangat penting untuk menjaga kehandalan mesin untuk menjamin suplai listrik ke masyarakat Makassar.

Berdasarkan observasi yang telah dilakukan di PT PLN Sektor Tello, ditemukan beberapa komponen pada mesin tenaga elektrik diesel yang mengalami kerusakan sehingga berdampak kerugian. Oleh karena itu, diperlukan perencanaan preventive maintenance yang baru untuk menghindari terjadinya kerusakan dan memaksimalkan pendistribusian aliran listrik.

Penelitian ini menggunakan metode kuantitatif dengan melakukan survey, observasi, interview, dan proses analisis dokumen yang dimiliki oleh perusahaan. Pada Gambar 3 memperlihatkan metode pelaksanaan penelitian. 

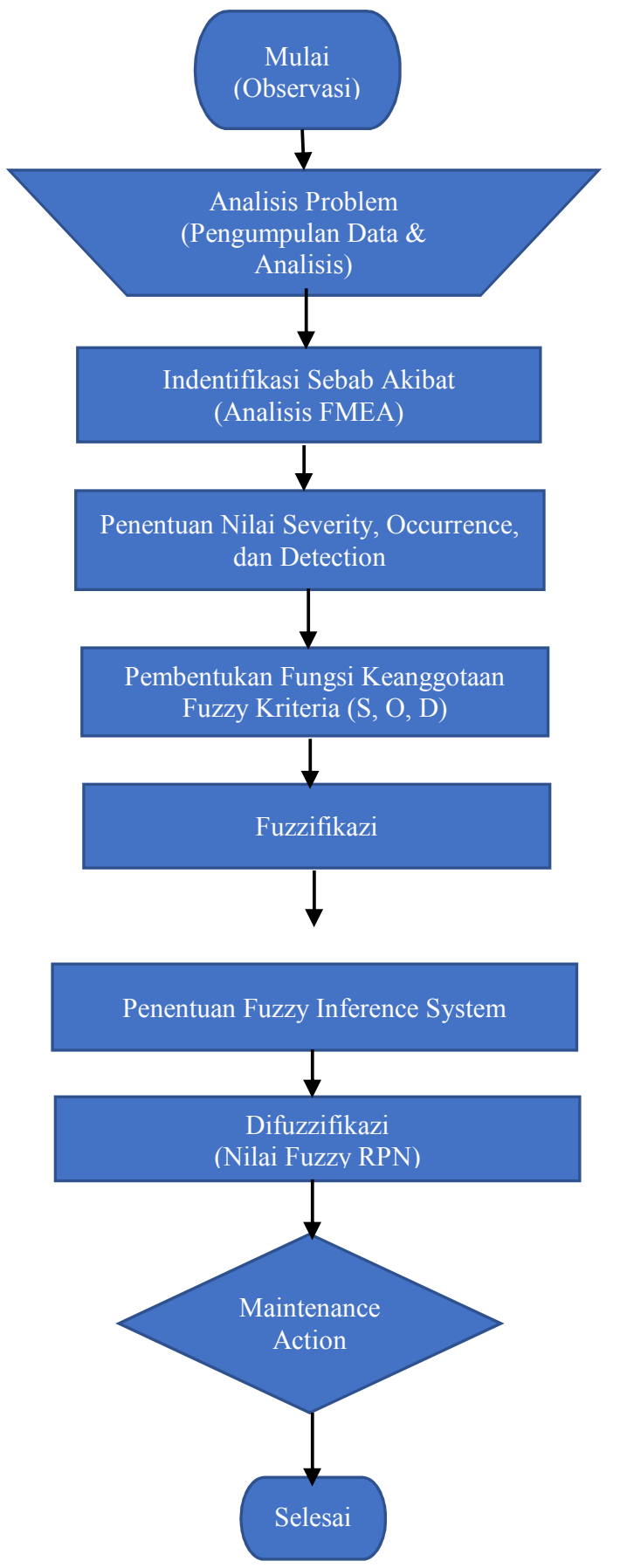

Gambar 3. Alur Penelitian

FMEA digunakan untuk mengidentifikasi komponen mesin yang sering mengalami kerusakan, jenis kerusakan dan penyebab kerusakan. Hasil dari proses analisis tersebut adalah tipe kerusakan yang potensial terjadi pada proses produksi, dampak dari kerusakan, dan prioritas komponen mesin yang akan dilakukan perbaikan berdasarkan nilai tertinggi Fuzzy RPN.

Berdasarkan penelitian sebelumnya, (9) metode perhitungan Fuzzy RPN menggunakan menggunakan metode Three Triangular Fuzzy Number. Perhitungannya sebagai berikut:

1. Menentukan nilai variabel linguistik dari setiap saverity, occurance, dan detection.

2. Mendefinisikan nilai linguistik ke dalam fungsi anggota triangular sebagai berikut:

$$
\mathrm{M}=(l, m, u)
$$

3. Mengalikan setiap nilai saverity, occurance, dan detection menggunakan rumus sebagai berikut:

$$
\begin{aligned}
& F R P N=S \times O \times D \\
&=\left(l_{1}, m_{1}, u_{1}\right) \times\left(l_{2}, m_{2}, u_{2}\right) \times \\
&\left(l_{3}, m_{3}, u_{3}\right) \\
&=\left(l_{1}, l_{2}, l_{3}\right) \times\left(m_{1}, m_{2}, u_{2}\right) \times \\
&\left(u_{1}, m_{3}, u_{3}\right)
\end{aligned}
$$

S Nilai dari dampak kerusakan dan ketidaktersediaan sparepart, nilai ditentukan berdasarkan kesepakan bersama expertise.

O Frekuensi terjadinya kerusakan selama proses produksi.

D Kemudahan dalam mendeteksi terjadinya kerusakan.

Nilai dari S, O, D berada pada skala 1-10. Hasil perhitungan dari FRPN untuk setiap komponen mesin yang dianalisis, yang memiliki nilai paling tinggi mengindikasikan bahwa koponen tersebut mempunyai tingkat resiko paling tinggi (10).

4. Proses Fuzzifikasi menggunakan rata-rata dari maksimum Difuzzifikasi. Salah satu metode Difuzzifikasi adalah Mean of Maxima (MOM). Metode ini digunakan mencari nilai rata-rata nilai crisp yang mempunyai nilai fuzzy maksimum. Berikut adalah formulasi yang digunakan 
dalam metode ini yang dikembangkan oleh (9):

$$
x=\frac{\sum X_{i} \in X_{i}}{|M|}
$$

\section{Hasil Penelitian}

Berdasarkan studi kasus yang dilakukan di PT PLN Sektor Tello Makassar, ditemukan bahwa beberapa komponen dari mesin generator mengalami kegagalan saat mesin sedang beroperasi, sehingga membutuhkan perencanaan perawatan pencegahan (preventive maintenance) untuk mencegah terjadinya kerusakan saat mesin dalam proses operasi. Sebelum melakukan tindakan korektif, analisis mengenai tipe kerusakan yang sering muncul serta pengaruhnya diperoleh dengan menggunakan metode FMEA yang ditujukan pada Tabel 1:

Tabel 1. Analisis FMEA

\begin{tabular}{|c|c|c|c|c|c|c|}
\hline Item & Jenis Kegagalan & Akibat Kegagalan & Penyebab Kegagalan & $\begin{array}{l}\text { हैे } \\
\text { हैँ }\end{array}$ & 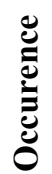 & 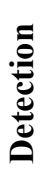 \\
\hline \multirow[t]{6}{*}{ SW Diesel } & $\begin{array}{l}\text { Elemen radiator JCW } \\
\text { fan A bocor }\end{array}$ & $\begin{array}{l}\text { Temperatur air } \\
\text { pendingin agak tinggi } \\
\text { tapi masih dalam batas }\end{array}$ & $\begin{array}{l}\text { Packing elemen radiator } \\
\text { bocor }\end{array}$ & 7 & 6 & 3 \\
\hline & $\begin{array}{l}\text { Ketukan keras pada } \\
\text { Cylinder }\end{array}$ & Operasi terhenti & $\begin{array}{l}\text { Kegagalan pada sistem } \\
\text { pelumas }\end{array}$ & 8 & 6 & 3 \\
\hline & $\begin{array}{l}\text { Pipa pelumas CVS } \\
\text { sisi outlet dari engine } \\
\text { bocor }\end{array}$ & $\begin{array}{l}\text { Operasi akan terhenti } \\
\text { jika kondisi mesin } \\
\text { dalam rusak parah }\end{array}$ & $\begin{array}{l}\text { Kebocoran pada packing } \\
\text { pipa pelumas CVS }\end{array}$ & 8 & 6 & 3 \\
\hline & $\begin{array}{l}\text { Coupling pompa } \\
\text { jacket cooling water } \\
\text { pecah/retak }\end{array}$ & $\begin{array}{l}\text { Proses dialikan pada } \\
\text { pompa lain }\end{array}$ & $\begin{array}{l}\text { Coupling pompa jacket } \\
\text { cooling } \\
\text { pecah/retak }\end{array}$ & 6 & 5 & 4 \\
\hline & $\begin{array}{l}\text { Jalur cepat pelumas } \\
\text { CVS bocor }\end{array}$ & Operasi terhenti & O-Ring valve CVS rusak & 8 & 6 & 3 \\
\hline & $\begin{array}{l}\text { Fuel oil booster pump } \\
\text { selalu trip }\end{array}$ & Operasi terhenti & $\begin{array}{l}\text { Filter bahan bakar tidak } \\
\text { berfungsi } \\
\text { baik/kotor }\end{array}$ & 8 & 5 & 3 \\
\hline \multirow[t]{4}{*}{ Mitsubishi } & $\begin{array}{l}\text { Tekanan minyak } \\
\text { pelumas Rocker Arm } \\
\text { rendah }\end{array}$ & Operasi terhenti & $\begin{array}{l}\text { Elemen filtter sudah } \\
\text { kotor }\end{array}$ & 9 & 4 & 4 \\
\hline & $\begin{array}{ll}\text { Unit } & \text { sulit } \\
\text { dioperasikan } & \end{array}$ & Operasi terhenti & Semua Pilot Start kotor & 9 & 3 & 3 \\
\hline & $\begin{array}{lr}\text { V-Belt } & \text { Radiator } \\
\text { Cooling } & \text { Tower lepa } \\
\text { dari dudukannya }\end{array}$ & $\begin{array}{l}\text { Operasi } \\
\text { berlangsung }\end{array}$ & $\begin{array}{l}\text { V-Belt Radiator Cooling } \\
\text { Tower putus }\end{array}$ & 8 & 4 & 3 \\
\hline & $\begin{array}{l}\text { Tali Fn Belt radiator } \\
\text { intercooler lepas }\end{array}$ & $\begin{array}{l}\text { Operasi } \\
\text { berlangsung }\end{array}$ & $\begin{array}{l}\text { Tali Fan Belt radiator } \\
\text { intercooler lepas }\end{array}$ & 6 & 4 & 4 \\
\hline
\end{tabular}

Setelah melakukan analisis kegagalan (failure analysis) untuk menentukan nilai Saverity (S), Occurence (O), dan Detection (D) pada Tabel 1 maka dilanjutkan dengan menghitung nilai Fuzzy FMEA untuk menentukan komponen mesin yang mendapat prioritas penanganan preventive maintenance pada mesin generator. Prioritas penanganan dilihat dari nilai FRPN yang merupakan hasil perhitungan dari Fuzzy FMEA dengan menggunakan microsoft excel. Perhitungan FRPN diperlihatkan pada Tabel 2. 
Tabel 2. Perhitungan Fuzzy RPN

\begin{tabular}{|c|c|c|c|c|c|c|c|c|c|c|c|c|c|c|c|c|}
\hline \multirow{2}{*}{ No } & \multicolumn{3}{|c|}{ FMEA } & \multicolumn{9}{|c|}{ Fuzzy } & \multicolumn{3}{|c|}{ FRPN } & \multirow{2}{*}{$\begin{array}{c}\text { Defuzzifikasi } \\
\text { RPN }\end{array}$} \\
\hline & $\mathbf{S}$ & O & D & & $\mathbf{S}$ & & & $\mathrm{O}$ & & & D & & $\mathbf{S}$ & O & D & \\
\hline 1 & 7 & 6 & 3 & 6 & 7 & 8 & 5 & 6 & 7 & 2 & 3 & 4 & 60 & 126 & 224 & 136,67 \\
\hline 2 & 8 & 6 & 3 & 7 & 8 & 9 & 5 & 6 & 7 & 2 & 3 & 4 & 70 & 144 & 252 & 155,33 \\
\hline 3 & 8 & 6 & 3 & 7 & 8 & 9 & 5 & 6 & 7 & 2 & 3 & 4 & 70 & 144 & 252 & 155,33 \\
\hline 4 & 6 & 5 & 4 & 5 & 6 & 7 & 4 & 5 & 6 & 3 & 4 & 5 & 60 & 120 & 210 & 130,00 \\
\hline 5 & 8 & 6 & 3 & 7 & 8 & 9 & 5 & 6 & 7 & 2 & 3 & 4 & 70 & 144 & 252 & 155,33 \\
\hline 6 & 8 & 5 & 3 & 7 & 8 & 9 & 4 & 5 & 6 & 2 & 3 & 4 & 56 & 120 & 216 & 130,67 \\
\hline 7 & 9 & 4 & 4 & 8 & 9 & 10 & 3 & 4 & 5 & 3 & 4 & 5 & 72 & 144 & 250 & 155,33 \\
\hline 8 & 9 & 3 & 3 & 8 & 9 & 10 & 2 & 3 & 4 & 2 & 3 & 4 & 32 & 81 & 160 & 91,00 \\
\hline 9 & 8 & 4 & 3 & 7 & 8 & 9 & 3 & 4 & 5 & 2 & 3 & 4 & 42 & 96 & 180 & 106,00 \\
\hline 10 & 6 & 4 & 4 & 5 & 6 & 7 & 3 & 4 & 5 & 3 & 4 & 5 & 45 & 96 & 175 & 105,33 \\
\hline
\end{tabular}

Berdasarkan hasil perhitungan Fuzzy RPN pada Tabel 2, terdapat empat koponen mesin yang perlu mendapat prioritas tindakan preventive maintenance. Empat komponen tersebut adalah Cylinder yang berdampak pada sistem pelumas, pipa pelumas CVS, jalur cepat pelumasan CVS, dan Rocker Arm.

\section{Kesimpulan}

Pada penelitian ini, nilai Fuzzy RPN yang digunakan sebagai batas wajib pemberian usulan tindakan adalah berdasarkan nilai tertinggi dari perhitungan Fuzzy RPN. Nilai ini ditetapkan dari hasil perkalian fuzzifikasi nilai Saverity, Occurrence, dan Detection. Nilai dari Fuzzy RPN selanjutnya dilakukan defuzzifikasi RPN dengan mengambil nilai tertinggi. Dalam penelitian ini, tindakan perbaikan yang akan ditetapkan pada PT PLN Sektor Tello adalah sebagai berikut:

a. SW Diesel

1. Cylinder

Penyebab terjadinya ketukan keras pada Cylinder adalah kegagalan pada sistem pelumasan. Tindakan perbaikan yang diusulkan adalah penyetelan clearance inhaust valve dan exhaust valve.

2. Pipa pelumas CVS

Penyebab terjadinya kerusakan pada pipa adalah kebocoran pada packing pipa. Tindakan perbaikan yang diusulkan adalah O-Ring diganti.

3. Jalur cepat pelumasan CVS

Penyebab terjadinyya kebocoran pipa adalah O-Ring valve CVS rusak. Tidakan perbaikan yang diusulkan adalah dengan mengganti O-Ring.

b. Mitsubishi

\section{Rocker Arm}

Penyebab terjadiya tekanan minyak yang rendah pada Rocker Arm adalah elemen filter sudah kotor. Usulan tindakanperbaikan adalah dengan membersihkan Filter.

\section{Saran}

Penelitian lebih lanjut dapat menggunaka mathlab dalam perhitungan nilai fuzzy RPN untuk membandingkan hasil perhitunga secara manual.

\section{Daftar Pustaka}

1. Kanti Bose T. Application of Fishbone Analysis for Evaluating Supply Chain and Business ProcessA Case Study on the ST James Hospital. Int J Manag Value Supply Chains [Internet]. 2012 Jun 30 [cited 2019 Jan 16];3(2):17-24. Available from:http://www.airccse.org/journal/ mvsc/papers/3212ijmvsc02.pdf 
2. Syawalluddin MW. Pendekatan Lean Thinking Dengan Menggunakan Mengggunakan Metode Root Cause Analysis Untuk Mengurangi Non Value Added Activities. (2):15.

3. Sutrisno A, Gunawan I, Tangkuman S. Modified Failure Mode and Effect Analysis (FMEA) Model for Accessing the Risk of Maintenance Waste. Procedia Manuf [Internet]. 2015 [cited 2019 Sep 19];4:23-9. Available from: https://linkinghub.elsevier.com/retrie ve/pii/S2351978915011269

4. McDermott RE, Mikulak RJ, Beauregard MR. The basics of FMEA [Internet]. New York: CRC Press; 2009 [cited 2019 Sep 19]. Available from:

http://www.books24x7.com/marc.asp ?bookid=37037

5. Widianti T, Firdaus H. Pengujian Suhu Lemari Es Dengan Metode Terintegrasi Fuzzyfailure Mode And Effect Analysis (fuzzy-FMEA). J Stand [Internet]. 2016 Mar;18(1):923. Available from: http://lipi.go.id/publikasi/pengujiansuhu-lemari-es-dengan-metodeterintegrasi-fuzzy-failure-mode-andeffect-analysis-fuzzy-fmea/21262
6. Rohani yoyok. Penentuan Fire Strength Pada Fuzzy Menggunakan Microsoft Excel, Studi Kasus: Keputusan Memilih Sepeda Motor. 2016 Mar;7(1).

7. Ningsih N, Pambudi NT, Abadi AM. Penerapan Metode Fuzzy Mamdani untuk Memprediksi Penjualan Gula. $2017 ; 8$.

8. Abrori M, H. Prihamayu H. Aplikasi Logika Fuzzy Metode Mamdani Dalam Pengambilan Keputusan Penentuan Jumlah Produksi. Karunia. 2015 Oct;XI(2):91-9.

9. Hayati M, Khorramabad, Iran, Reza Abroshan M, Zanjan. Risk Assessment using Fuzzy FMEA (Case Study: Tehran Subway Tunneling Operations). Indian J Sci Technol [Internet]. 2017 Feb 1 [cited 2019 Nov 15];10(9):1-9. Available from: http://www.indjst.org/index.php/indjs t/article/view/110157

10. Lo H-W, Liou JJH, Huang C-N, Chuang Y-C. A novel failure mode and effect analysis model for machine tool risk analysis. Reliab Eng Syst Saf [Internet]. 2019 Mar [cited 2019 Sep 19];183:173-83. Available from: https://linkinghub.elsevier.com/retrie ve/pii/S0951832018307129 